\title{
International news flow cooperative study
}

A media cooperative study of foreign news and international news flow in the 1990 s is under way. The objective is to define a New World (Dis)order geography of news gathering. PNG and other Pacific nations are involved.

\section{By SORARIBA NASH}

THE SOUTH PACIFIC Centre for Communication and Information in Development (SPCenCIID) of the University of Papua New Guinea is participating in a worldwide research project on foreign news flow. The project is being coordinated jointly by Professor Annabelle Sreberny-Mohammadi, of the University of Leicester, United Kingdom; and Professor Robert L. Stevenson, University of North Carolina, USA. The rationale behind this study stems from the fact that the end of the Cold War demands new maps, both cartographic and conceptual. The many political and technological changes of the past decade have in their various ways produced changes that the old maps cannot register. The schema of three (or four) worlds, of developed centers and underdeveloped peripheries have given way to market globalisation and a New World (Dis)order.

Before 1989, the international geography of news gathering seemed to have solidified into a pattern structured on Cold War rivalries and tensions. ${ }^{2}$ Now that the Cold War is over and old barriers are starting to crumble, we need to map out this new pattern as well as identifying how and at what rate the new technology is providing easy access to international news flow from country to country.

A domestic survey domestic was carried out by Electronic Media I students from SPCenCIID to determine which of the two daily newspapers - PostCourier and The National - is most widely read. Their findings are presented as a sub-topic following the conclusion of this paper.

\section{Progress on the project to date}

With the help of three groups of people involved in the survey - Iroa Pamoa (BJRN III), monitoring NBC bulletins; news director John Eggins and his staff 
recording EM TV news, Philip Kepson from The National and Otto Avorosi (BJRN III) monitoring the newspaper stories, and myself coordinating on behalf of SPCenCIID, we completed the pilot project within two weeks. The chosen dates for the pilot project were May 8-9 - the end of World War II, 50 years ago in Europe.

It took us a little over two weeks to analyse and compile data and then send off the data plus newspaper cuttings, audio and video tapes to Professor Stevenson. On July 27, we received an encouraging word via electronic mail from Professor Stevenson who received our data by post:

I just received the materials you sent, Annabelle. Your contribution was by far the most thorough and best organized of any I have received so far. We've data from Kenya, Austria, PNG and Iceland is in the mail. It's a fantastic accomplishment already, and the next phase will be even bigger. Thanks for the splendid work.

Bob.

From this experience we are embarking on the big project in September 1995. This will be quite intensive and it will run for two weeks, starting on the September 3 and ending on September 23. The PNG team will be monitoring the news traffic about the Beijing conference. All news media will be used again in this case.

The UN Conference in Beijing actually starts on the September 4, and because there is a possibility that the event might not have a huge coverage, other dominant international stories within that period will have to be selected also. For this reason, we are starting the observation on August 28 which is the NGO activity week, prior to the main event. Again - after the nominated period has elapsed, the observations will continue for some weeks thereafter in order to catch up with any major round-ups or news summaries.

Our major assignment here is to catch as much of the coverage of the Beijing event in all the news channels we are examining: EM TV, Post-Courier, The National, NBC, Nau FM and the Saturday Independent. A summary of the project will be published in a single volume with Sreberny-Mohammadi and Stevenson as editors. Each country will have a chapter. The SPCenCIID team will produce the PNG chapter.

\section{Justification of project}

The project is of great value and relevance to PNG because our findings will update various studies done for UNESCO in the past. The findings and the summary data will become useful to many researchers, students of mass 


\section{SORARIBA NASH}

communication, and, most important of all, Papua New Guinea will be included in an international textbook on international news flow. The two-day survey was carried out as a pilot project on qualitative analysis and source analysis of international news flow before the two weeks intensive assignment for monitoring the Beijing conference in September. The Beijing event is the Fourth United Nations' World Women's Conference. The conference will be attended by participants from all United Nations member countries where women are expected ${ }^{4}$ to 'present ideas and offer strategies in an attempt to negotiate a global platform for action'. Papua New Guinea is sending a delegation.

The lead-up to the subject of this study was the focus on media coverage of the 50th anniversary of the end of the Second World War in Europe, commemorated as Victory in Europe, or VE, day. It was felt that the story on the commemoration of VE day would be interesting for number of reasons. First, it provided material for analysis of how media reconstruct an international event. What historical footage and images are used to write the story? Given that radio provided the most immediate news coverage then, how is the story represented on television? Who is interviewed, whose memories are invoked, what moments of the event are focused on, and what contemporary interpretations are provided?

Second, given that these dates are only the end of the war in Europe, and that despite the name, the whole world was not involved in the war, it might be the subject of media analysis of how the 'world' has changed, of comparisons between then and now, and particularly of changed international allegiances. Is the story presented as solely 'foreign?' What kinds of domestic links and angles are developed? Is it given any prominence as an epochal event?

This was a voluntary, collaborative effort to produce a large and detailed portrait of international news and global news flow in the 1990s, and I accepted the challenge on behalf of SPCenCIID. Dr Suzanna Layton, of the University of Queensland, assisted us by providing background briefing as well as the contact point to the project directors in the initial stages.

\section{Background}

Up until 1989, the international geography of news gathering seemed to have an established pattern in place, 'structured on Cold War rivalries and tensions'. A number of news flow studies carried out in the 1980s showed similar set pattern of news coverage. This was a clear indication that certain news channels from the United States and Western Europe stood out as newsmakers, including 'hot spots' of the Third World crises and the world of state socialism or communism. The South, on the other hand, knew little about other nations within its own region, but the news patterns were identified as 'known'. 
INTERNATIONAL NEWS FLOW

International news flows were dominated by the 'big four' Western news gathering agencies - Agence France-Presse, Associated Press, Reuter and United Press International. There was an imbalance in news flow with the Third World receiving far more material about the First World than vice versa. Such evidence and arguments culminated in the demand for New World Information and Communication Order (NWICO), politicising debates within UNESCO and the Non-Aligned movement, thus leading to the withdrawal of the United States, United Kingdom, and Singapore from UNESCO during the 1984-1985 period.

The news environment has changed quite radically since 1989 . The changes have been profound politically and technologically. New forces of nationalism, new struggles for development and democracy, new concerns about human rights and environment - all compete to attract news media attention. Given the prevailing situation of 'such flux and crisis', the questions on what should be the international agenda - becomes very important.

\section{Rapid change}

Despite the existence of uneven media access between the industrialized North and South, broadcast signals have become increasingly available to more and more people around the world with the aid of satellite dishes. News gathering has changed also with the fast disseminating ability of television news, perhaps the key and new ingredient in the global news environment.

In Papua New Guinea, changes have been quite dramatic. Apart from some international news agency feeds, availability of many satellite dishes and cable network enables PNG's town and city comsumers with access to TV especially in major towns and cities - to tune into most Australian channels like ABC, SBS, Channel Ten, and the Nine Network. CNN is also viewed in PNG. Some cable-controlled services also received are the Discovery Channel, ESPN, HBO - the movie channel - plus TNT, the cartoon network. Because of the proximity of the Indonesian-owned Palapa satellite, some Malaysian and Indonesian channels and Singapore-based Business Asia are received. A Chinese Cable Channel in Mandarin is received also by those who pay for the service.

Other than broadcast TV as the agent of 'hot and fast' news relay medium, there are about 13 foreign networks by satellite and several cable TV companies serving the Papua New Guinea audience. Print media receives feeds from specialised services like PACNEWS, the Telegraph Mirror, The Independent as well as the main agencies like: AAP, AP, Gemini, NZPA, AFP, Reuters and PA. 


\section{SORARIBA NASH}

\section{Summary on data collected}

The news medium monitored for this survey were two daily newspapers, one radio network, and one television station. Countries of the world were categorised in regions. Papua New Guinea naturally got placed under the AsiaPacific region. According to the geographical coding, Papua New Guinea was allocated the code number 728 among more than 40 countries listed under the category.

Therefore, before indicating the medium, date, story ID, type of story, length and source, each time we had to name the country as: 728. Other Pacific Island countries listed as participants included Fiji, Kiribati, Marshall Islands, Nauru, Solomon Islands, Tonga, Tuvalu, Vanuatu and Western Samoa. Australia and New Zealand were also included.

\section{Newspapers:}

PNG Post Courier (newspaper) was identified as medium $=1$

The National (newspaper) as medium $=2$

The papers carried some stories about the VE day on schedule so we were able to code them according to instructions. After giving story ID and other particulars, we had to cut up the stories and paste them up below the coded forms. Apart from the coded forms, second lot of same newspaper editions were also enclosed untouched.

\section{Radio:}

The National Broadcasting Commission (NBC) of Papua New Guinea. NBC: Broadcaster No. $1=4$

The radio network surprisingly carried no stories regarding the VE day in their main bulletins (7am, 12 midday, and 7 pm) throughout May 8-9. When we talked to the wire service editor, he said the network received a number of VE day stories through Radio Australia (RA) wire service and the Australian Associated Press (AAP) and that he had placed them in the main subeditor's tray but they were not included in any of the bulletins. Prior to scheduled dates of the two-day pilot project, we faxed NBC, requesting their cooperation twice but no replies were made. We used walkmans and stereo sets to monitor and record the radio bulletins. We were forced to conclude that the radio network did not run any stories about the VE day throughout May 8-9.

\section{Television:}

EM TV: Broadcaster No. $2=5$

EM TV ran stories and pictures about VE day starting on May 6. There were no items concerning VE day on the May 7, 8 and 9 bulletins. EM TV staff, under the guidance of news director John Eggins, cooperated well. We sent two tapes containing the EM TV News bulletins on May 8-9 only. The tapes were kindly provided by the TV station, as well as doing the dubbing free of charge. 


\section{Conclusion}

It is true to say that 'broadcast signals are available to more and more of the world's population. Backed by the changing technology, news gathering has changed also, with the rapid distribution of live television news'. There are also new corporate and regional players in the international news provision, with $\mathrm{CNN}_{8}, \mathrm{BBC}$ World Service Television and Reuters among the major global players. The tendency toward global concentration and distribution of video news footage might be even more marked than the 'big four' domination of wire service news in the 1970s. There has also been a growth of Southern international news gathering agencies attempting to provide something of a 'contra flow' to the Western agency news flows. There is also a new tier of organisational actors - the regional news exchanges - which take in mainly non-regional news feeds from the agencies and distribute them to their respective national broadcasting organizations.

Judging by the available sources or feeder agencies and the almost instantaneous international news flow into Papua New Guinea, it would appear that international news flow has corrected itself from the traditional Western domination of the 1970s. However, access to media into the scattered majority in very remote parts of PNG and most of the third world countries is still 'radically uneven'.

I would contend from observing CNN, ABC, Channel Ten and SBS that the news flow from the developing world or the Third World into the international feeder system to make the news consumption packages for the First World audience is not balanced at all, compared to what comes down from the First World regions. We tend to receive more from the outside news agencies than what goes out from us. But to what extent the imbalance differs cannot be determined until the completion of the Beijing project and eventually when we receive and review the final data. Only then would we know if the gap is narrowing or increasing.

\section{Notes:}

Sreberny-Mohammadi, A. and Stevenson, Robert L. (1995): Project Proposal: Cooperative Study of Foreign News and International News Flow in the 1990s; p.1

Ibid.

Electronic mail from Professor R. L. Stevenson, 27 July 1995.

4 Daure, M, '74-member team for Beijing meet', The National, 3 August 1995 , p. 20.

Sreberny-Mohammadi and Stevenson, Op cit., p. 2

Sorariba, N. G. (1995): 'Papua New Guinea: Mass Media', a summary accompanying the Pilot Study of May 8-9, 1995. Submitted as part of PNG data to Professor R L Stevenson, University of North Carolina, USA. 
Sreberny-Mohammadi and Stevenson, Op. cit., p. 2

Ibid., p. 2

Ibid., p. 1

10 Sorariba, N. G. (June 1995): ‘Newspaper Readership Survey', questionaire and data, SPCenCIID, UPNG, Port Moresby. Unpublished.

Ibid. Data summary.

12 Map, Winis, 'TV viewers outsurip newspaper readers', Uni Tavur19 May 1995, p. 7.
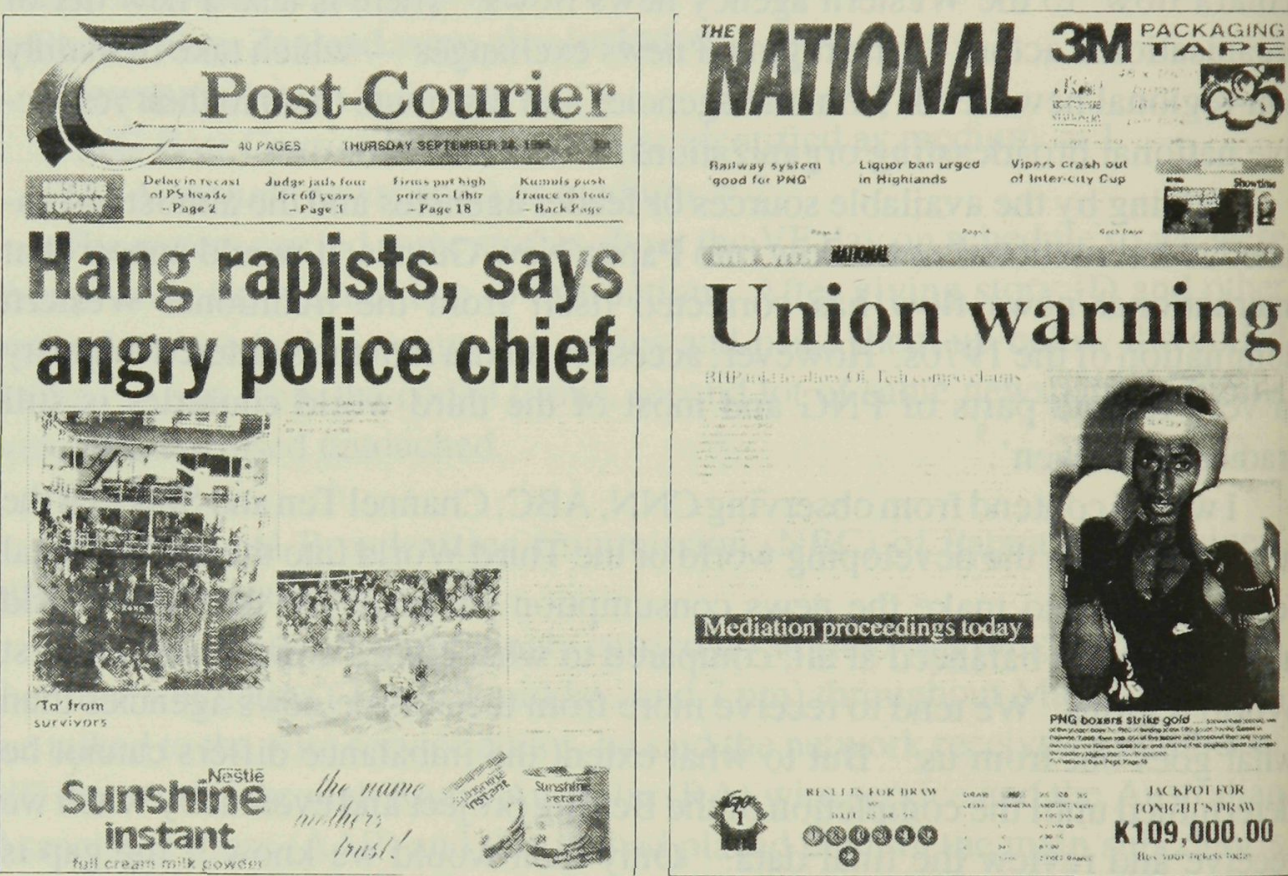

The Post-Courierand The National... research into readership.

\section{Popularity of the papers}

IN REPLY to the challenge whether we do research to determine which of the Papua New Guinea daily newspapers - Post-Courier and The National - is read widely, I am pleased to disclose our findings from the independent research carried out by the Electronic Media I students from SPCenCIID throughout the first semester of 1995. We used random sampling. Selection of the quota was tightly controlled. This means team members had to go out into the city. The sampling was done over four months - March, April, May and June 1995 because the two daily newspapers were running promotional campaigns (com- 
petitions for readers to win prizes) which affected normal sale figures. So we had to extend the period of sampling in order to monitor any major variation on sales and readership attitude. The questionnaire went out during the beginning of March to enable team members to target their population sample. The population sample was made up of people ranging from managers, bankers, air hostesses, clerks and lecturers to security guards, university students, high school students, cleaners and betelnut vendors to self-employed individuals. The ages ranged from 12 to 79 .

The purpose of the research was three-fold. First part was designed to determine how many people within the selected sample buy newspapers. Secondly, How often do they buy papers and which paper do they buy? And finally why do they prefer what they buy?

Of the 400 sample population, 70 per cent preferred the Post-Courier. This was made up of 40 per cent male and 30 per cent female. Reasons ranged from: 'Because they put birthday greetings', 'I'm used to the Post-Courier', 'better comics and crossword', 'Weekend Magazine', 'more provincial news to indepth national and international news', 'more accurate and experienced reporters', to 'good research'. '

Twenty eight per cent opted for The National — 15 per cent male and 13 per cent female. Reasons given were: 'Very informative and interesting articles', 'in-depth coverage of both national and international news', 'better 11 format than Post-Courier', 'more sports news', 'clear and colorful pictures'. '

Two per cent said they cannot read. One per cent said they did not care, while the other one per cent said they like The National's colorful pictures.

The Post-Courier is still the favorite over The National. This conclusion confirms findings by a Uni Tavur/SPCenCIID survey published on 19 May 1995. The random sampling survey in Port Moresby showed 45 per cent reading the Post-Courier and its rival National had a 36 per cent readership. The weekly Times of PNG had seven per cent, Wantok three percent and UPNG journalism student newspaper Uni Tavur two per cent readership.

$\neg$ Sorariba Nash is Lecturer in Journalism at the University of PNG's South Pacific Centre for Communication and Information in Development (SPCenCIID). This article is based on his current research project. 